\title{
Effect of Polymer Hydrophilicity and Molar Mass on the Properties of the Protein in Protein-Polymer Conjugates: The Case of PPEylated Myoglobin
}

\author{
Chiara Pelosi, Celia Duce, Frederik R. Wurm,* and Maria R. Tinè
}

Cite This: Biomacromolecules 2021, 22, 1932-1943

Read Online

ACCESS 1

山ll Metrics \& More

回国 Article Recommendations

Supporting Information

ABSTRACT: Polyphosphoesters (PPEs), a versatile class of biodegradable and biocompatible polymers, have been proposed as alternatives to poly(ethylene glycol) (PEG), which is suspected to be responsible for anaphylactic reactions in some patients after the administration of PEGylated compounds, e.g., in the current Covid-19 vaccines. We present the synthesis and characterization of a novel set of protein-polymer conjugates using the model protein myoglobin and a set of PPEs with different hydrophilicity and molar mass. We report an extensive evaluation of the (bio)physical properties of the protein within the conjugates, studying its conformation, residual activity, and thermal stability by complementary techniques (UV-vis spectroscopy, nano-differential scanning calorimetry, and fluorometry). The data underline the systematic influence of polymer hydrophilicity on protein properties. The more hydrophobic polymers destabilize the protein, the more hydrophilic PPEs protect against thermally induced aggregation and proteolytic degradation. This basic study aims at guiding the design of future PPEylated drugs and protein conjugates.

\section{INTRODUCTION}

Poly(ethylene glycol) (PEG) is probably the most common water-soluble polymer in the biomedical field. Covalent attachment of PEG to proteins, peptides, and other drugs (known as "PEGylation") is used to improve their pharmacokinetics. ${ }^{1}$ Despite the current use, PEGylated drugs have recently raised some concerns related mostly to the formation of anti-PEG antibodies ${ }^{2}$ and the polymer accumulation in the body after long-term treatments. ${ }^{3}$ In the past months, PEGylated lipids used in the first Covid-19 vaccines (Pfizer and Moderna) were suspected to be responsible for allergic reactions in some patients after the vaccine administration. ${ }^{4}$

These investigations firmly push the research of PEG alternatives, also including biodegradable polymers. ${ }^{5-8}$ Among these alternatives, polyphosphoesters (PPEs) are a promising degradable alternative to PEG. ${ }^{9,10}$ For the past 20 years, several new PPEs have been synthesized and they have proven their biocompatibility in vitro (in terms of cytocompatibility ${ }^{9}$ and "stealth effect"1,12) hydrolytic and/or enzymatic degradability, ${ }^{13-15}$ and they have shown some promising in vivo results as drug nanocarriers. ${ }^{16}$ The major strength of PPEs is their chemical versatility: the pentavalent phosphorus in the main chain can be used to control the hydrolytic stability of the polymers and to perform postmodification reactions (e.g., in the presence of a double or triple bond in the lateral chain). ${ }^{17,18}$ Previous studies published by our group reported the conjugation of PPEs to several proteins, so-called "PPEylation", including bovine serum albumin, uricase, bovine liver catalase, maltose-binding protein, or myoglobin. ${ }^{19-23}$

Here, we describe the synthesis of a novel set of PPEylated protein-polymer conjugates with variable polymer hydrophilicity and molar mass. Unlike most of the other PEGsubstitute candidates, the properties of PPEs can be modulated by changing the lateral group of the polymer; therefore, we prepared a library of (co)polymers with different lengths and lateral chains to evaluate the influence of these parameters on the protein properties, and we compared the results to PEGylated controls. The effect of the polymer hydrophilicity on the conjugates' properties had been previously investigated with polyoxazolines, ${ }^{24}$ which have similarities to PPEs; however, they are not biodegradable. Besides, the previous articles intended to increase the enzymes' solubility in organic solvents. $^{25}$

Herein, we have chosen myoglobin of equine skeletal muscle as a model protein because it is a relatively small globular protein with an easy way to determine the residual activity and

Received: January 18, 2021

Revised: $\quad$ March 7, 2021

Published: April 8, 2021 
has a well-known 3D structure and unfolding mechanism. ${ }^{26,27}$ Myoglobin could be seen as a model for hemoglobin because it has the same cofactor and a similar tertiary structure around the active site but lower molar mass. As hemoglobin has several promising applications, e.g., the formation of cell-free oxygen carriers, ${ }^{28}$ studies on myoglobin are appealing and act as a first step for future more complex studies.

We evaluated the effect of the polymer attachment on the protein conformation, its residual activity, and its thermal stability employing complementary techniques (UV-vis spectroscopy, nano-differential scanning calorimetry, and fluorometry). Besides, we tested the protection of the PPEs against of proteolytic enzymes (i.e., Proteinase K). The analyses showed that the more hydrophobic polymers destabilized the protein after conjugation, while hydrophilic PPEs performed similarly to PEG. In particular, an increase of the polymer hydrophilicity resulted in higher protein activity, thermal stability, and higher protein protection against thermally induced aggregation and proteolysis.

This work answers several questions about the structureproperty relations in the conjugates, paving the way to design future PPEylated proteins with pharmaceutical interest and full biodegradability.

\section{EXPERIMENTAL SECTION}

2.1. Materials. The solvents (1,4-dioxane, 99\%, extra dry, anhydrous; acetonitrile (ACN), 99.9\%, extra dry; dichloromethane (DCM), 99.9\%, extra dry over molecular sieves, stabilized with amylene; benzene, 99\%, anhydrous) were purchased from AcroSeal Across Organics (Germany) and used as received unless otherwise specified. Dulbecco's phosphate-buffered saline without calcium and magnesium was purchased from Thermofisher (Itlay) and used as received for all the biochemical and biophysical analyses (UV-vis spectrometry, nano-DSF, nano-DSC, activity, and proteolytic assay). A $50 \mathrm{mM}$ borate buffer was prepared from sodium tetraborate $(50$ $\mathrm{mM})$ dissolved in distilled water $\left(\mathrm{Na}_{2} \mathrm{~B}_{4} \mathrm{O}_{7} \cdot 10 \mathrm{H}_{2} \mathrm{O}\right.$, Sigma-Aldrich, Germany), adding $\mathrm{HCl}(0.1 \mathrm{M})$ until reaching $\mathrm{pH}=8.8 . N, N^{\prime}$. Disuccinimidyl carbonate ( $N, N^{\prime}$-DSC), diethyl ether (purity $97.5 \%$, stabilized with BHT), myoglobin of the equine skeletal muscle (My) (purity 99.5\%), poly(ethylene glycol) methyl ether (average $M_{\mathrm{n}} 10$ and $20 \mathrm{kDa}$ ), 4-(dimethylamino)pyridine (DMAP) (purity $\geq 99 \%$ ), picrylsulfonic acid solution (TNBS) $5 \%(\mathrm{w} / \mathrm{v})$ in $\mathrm{H}_{2} \mathrm{O}$, diglycine (Gly-Gly), 2,2'-azinobis(3-ethylbenzothiazoline-6-sulfonic acid) diammonium salt (ABTS), hydrogen peroxide solution $(30 \%(\mathrm{w} / \mathrm{w})$ in $\mathrm{H}_{2} \mathrm{O}$, contains stabilizer), catalase from bovine liver (aqueous suspension, 40000-60000 units/mg protein), guanidine hydrochloride solution (6 M), sinapinic acid, and trifluoroacetic acid (99\%) were purchased from Sigma-Aldrich (Italy) and used as received. Proteinase $\mathrm{K}$ powder $(\geq 30 \mathrm{U} / \mathrm{mg})$ was purchased from Thermofisher and used as received. 1,8-Diazobicyclo[5.4.0] undec-7ene (DBU) from Sigma-Aldrich was dried, distilled, and stored at 0 ${ }^{\circ} \mathrm{C}$ over molecular sieves (4 ̊)). 2-(Benzyloxy)ethanol was purchased from $\mathrm{ABCR}$ distilled from sodium and stored at $0{ }^{\circ} \mathrm{C}$ over molecular sieves (4 ̊). Sephadex G-50 medium (Sigma-Aldrich) was left to swell in water overnight before use, following the proportion Sephadex/water $=10 \mathrm{~mL} / 50 \mathrm{~mL}$; when the column was not in use, it was stored in a solution of $5 \% \mathrm{EtOH}$ at $4{ }^{\circ} \mathrm{C}$.

2.2. Instrumentation and Characterization Techniques. For the analyses of the polymers, gel permeation chromatography (GPC) was performed in $\mathrm{N}, \mathrm{N}$-dimethylformamide (DMF; containing $0.25 \mathrm{~g} /$ $\mathrm{L}$ of lithium bromide as an additive) by using an Agilent 1100 Series as the integrated instrument, including a PSS GRAM columns (1000/ $1000 / 100 \mathrm{~g})$, a UV detector $(280 \mathrm{~nm})$, and an RI (refractive index) detector at a flow rate of $1 \mathrm{~mL} / \mathrm{min}$ at $60{ }^{\circ} \mathrm{C}$. Calibration was performed by using P.S. standards provided by the Polymer Standards Service. ${ }^{1} \mathrm{H},{ }^{13} \mathrm{C}$, and ${ }^{31} \mathrm{P}\{\mathrm{H}\} \mathrm{NMR}$ spectra were acquired at $298.3 \mathrm{~K}$ with Bruker AVANCE III 300, 500, or $700 \mathrm{MHz}$ spectrometers. The spectra were calibrated against the solvent signal and analyzed by using MestReNova 9.0.0 from Mestrelab Research S.L.

GPC in phosphate buffered saline (PBS, $100 \mathrm{mM}$ phosphate, 50 $\mathrm{mM}$ sodium chloride, $\mathrm{pH}=6.5$ ) was performed by using a Superdex column (10/300 GL, 200 increase), with $100 \mu \mathrm{L}$ injected at a flow rate of $1 \mathrm{~mL} / \mathrm{min}$. Elution profiles were detected by a UV detector (280 nm, Agilent 1260), a multiangle linear light scattering detector (Wyatt mini-DRAWN TREOS MALLS), and a differential refractive index detector (Agilent 1260), connected online in series, after the column. The purity and the average molecular weight of the conjugates were calculated as previously reported in our paper. ${ }^{19}$

MALDI-ToF measurements were performed as described by Wurm and co-workers ${ }^{22}$ on a Shimadzu Axima CFR MALDI-TOF mass spectrometer using sinapinic acid (3-(4-hydroxy-3,5-dimethoxyphenyl)prop-2-enoic acid) as a matrix. A solution of the samples (around $1 \mathrm{mg} / \mathrm{mL}$ of protein inside) in a TFA-acidic ( $0.01 \mathrm{vol} \%$ ) mixture of $\mathrm{H}_{2} \mathrm{O} / \mathrm{ACN}$ (50:50) was mixed with a solution of sinapinic acid $(10 \mathrm{mg} / \mathrm{mL})$. The samples were analyzed after the evaporation of the solvent.

Sodium dodecyl sulfate-polyacrylamide gel electrophoresis (SDSPAGE) was conducted mixing $20 \mu \mathrm{L}$ of the sample (at a concentration around $1 \mathrm{mg} / \mathrm{mL}$ of protein) with $10 \mu \mathrm{L}$ of a $4 \mathrm{x}$ Laemmli sample buffer, $6 \mu \mathrm{L}$ of water, and $4 \mu \mathrm{L}$ of 2 -mercaptoethanol as reducing agent, heating the final solution at $80{ }^{\circ} \mathrm{C}$ for $2 \mathrm{~min}$. For the samples' molecular weight analysis, $20 \mu \mathrm{L}$ of the final solutions was loaded on $10 \%$ Mini-PROTEAN TGX Stain-Free Protein Gels (10 wells, $30 \mu \mathrm{L}$ maximum loading). The electrophoresis was performed for $2 \mathrm{~h}$ at $120 \mathrm{~V}$, with 10x TGS running buffer from Biorad properly diluted by using precision plus protein standard molecular marker (Biorad, $10-250 \mathrm{kDa}$ ). The gel was washed with water and stained overnight with Bio Safe Coomassie G-250 stain solution. For the analysis of the proteolytic degradation, the samples (with protein concentration of $1 \mathrm{mg} / \mathrm{mL}$ ) were incubated with an excess of Proteinase $\mathrm{K}(1: 2 \mathrm{w} / \mathrm{w})$ for $4 \mathrm{~h}$ at $37{ }^{\circ} \mathrm{C}$. A $20 \mu \mathrm{L}$ aliquot of the solution was added to $4 \mathrm{x}$ Laemmli sample buffer, water, and 2mercaptoethanol in the proportions mentioned above. The electrophoresis was performed by using an analogue procedure, with the following differences: gel: 4-20\% Mini-PROTEAN TGX Stain-Free Protein Gels (10 wells, $30 \mu \mathrm{L}$ maximum loading); running conditions: $30 \mathrm{~min}$ at $200 \mathrm{~V}$; molecular marker: Precision Plus Protein Dual Xtra standard (from Biorad, 2-250 kDa); the gel was washed with water and fixed for 50 min with Coomassie Brilliant Blue R-250 destaining solution than stained for 70 min with Bio Safe Coomassie G-250 stain solution.

The protein concentration was determined by UV-vis absorbance spectrophotometry with a Jasco V-550 UV-vis spectrometer using the protein extinction coefficient $\varepsilon(280 \mathrm{~nm}): 1.66 \mathrm{~mL} / \mathrm{mg} \mathrm{cm},{ }^{29}$ considering that at this wavelength the polymer contribution is zero and that the protein has the same absorbance coefficient either alone or in the conjugates. Errors were evaluated based on at least three replicas.

The number of polymers attached to each protein was determined by comparing the data obtained by GPC with triple detection, MALDI-TOF, SDS-PAGE, and UV-vis absorbance analyses.

2.3. Synthesis. Details on the syntheses can be found in the Supporting Information, Part 1. The synthesis of the conjugate MyPEEP (4) was previously reported. ${ }^{19}$

General Procedure for Activation of PEG with $N, N^{\prime}-D S C$. The reaction was performed following a literature procedure, ${ }^{30}$ with some modifications. All glassware was flame-dried three times before use, and then the polymer was added to a $100 \mathrm{~mL}$ two-necked roundbottom flask and dissolved in $8 \mathrm{~mL}$ of dry dioxane. The DMAP was added to a $25 \mathrm{~mL}$ Schlenk tube and dissolved in $3 \mathrm{~mL}$ of dry ACN. $N, N^{\prime}$-DSC was added to a $50 \mathrm{~mL}$ Schlenk tube and dissolved in $6 \mathrm{~mL}$ of dry ACN. The $N, N^{\prime}$-DSC solution was transferred with a syringe to the round-bottom flask. The reaction was started with the slow addition of the DMAP solution to the flask, performed via syringe. After the desired time, the reaction product was directly precipitated from the clear solution to diethyl ether. The precipitation was repeated two times, and the product was dried overnight. The 
Scheme 1. Polymerization Scheme of Cyclic Phosphoesters with Subsequent $N, N^{\prime}$-DSC Activation

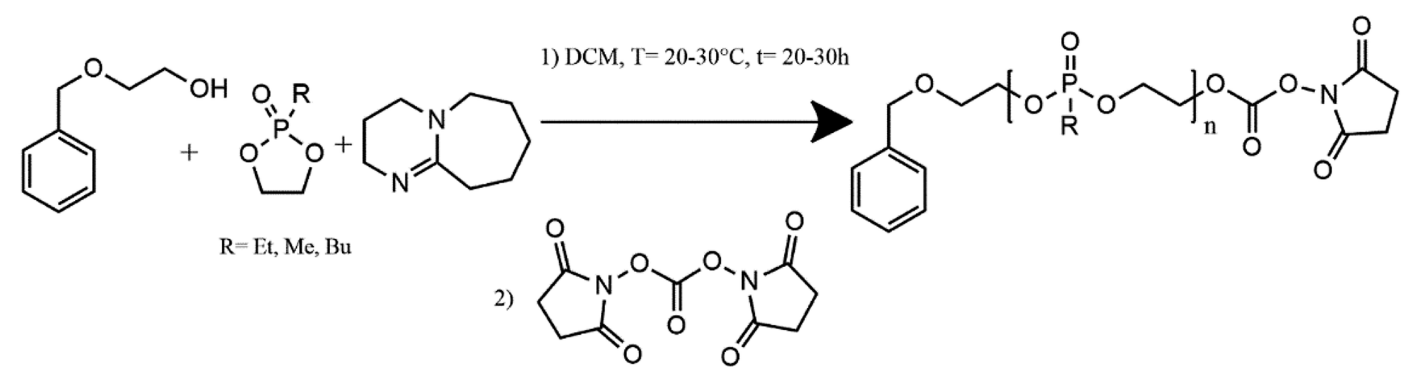

percentage of activation was determined by ${ }^{1} \mathrm{H}$ NMR and confirmed by ${ }^{1} \mathrm{H}$ DOSY NMR spectroscopy.

General Procedure for the Synthesis of PPES, SC-Activated. the reaction was performed following a literature procedure ${ }^{19}$ with some modifications. Two 25 and a $50 \mathrm{~mL}$ Schlenk tubes were flamed-dried under reduced pressure and purged with argon three times. The respective monomer(s) was weighted in the $50 \mathrm{~mL}$ Schlenk tube, dissolved in dry benzene, and dried three times by lyophilization. It was dissolved in dry dichloromethane to reach a concentration of 4 M. A stock solution of the initiator in dry DCM (0.2M) was prepared, and the calculated amount was added to the monomer solution. The solution was brought to the desired temperature. A stock solution of the catalyst DBU in dry DCM $(0.2 \mathrm{M})$ was prepared, and the polymerization was initiated by the rapid addition of 3 equiv of DBU (with respect to the initiator) to the solution with the monomer and initiator inside. The reaction was terminated after a specific time by adding an $N, N^{\prime}$-DSC solution in dry ACN $(40 \mathrm{mg} / \mathrm{mL})$ containing 5.0 equiv of the termination agents with respect to the initiator. The termination reaction was carried on for $2 \mathrm{~h}$; then the product was purified by three-times precipitation in cold diethyl ether, and the solvent was removed under reduced pressure, until constant weight, obtaining a yellow amorphous product. The polymer was characterized by ${ }^{1} \mathrm{H}$ and ${ }^{31} \mathrm{P}$ NMR; the percentage of activation was detected by the TNBS assay (performed as reported in the Supporting Information, Part 1) and confirmed by ${ }^{1} \mathrm{H}$ DOSY NMR spectroscopy. The partition coefficient $(\log P)$ of the polymers was estimated by ChemDraw Ultra (version 12, Cambridge Soft), analyzing two repeating units of the main chain.

General Procedure for the Conjugates' Synthesis. The reaction was performed following a procedure previously reported. ${ }^{19}$ The protein myoglobin was dissolved in a few milliliters of borate buffer ( $50 \mathrm{mM}, \mathrm{pH}=8.8$ ). The calculated amount of PPE-SC was divided into three parts, dissolved in a few milliliters of distilled water, and added dropwise to the protein solution, waiting $30 \mathrm{~min}$ between each portion's additions. The reaction was incubated at $21^{\circ} \mathrm{C}$ for $4 \mathrm{~h}$. The product was purified by dialysis against water $(\mathrm{MWCO}=50000 \mathrm{kDa})$ for $24 \mathrm{~h}$. Additional purification by gel permeation chromatography over Sephadex G-50 (water as the eluent) was performed. The fractions with desired purity were collected and lyophilized, yielding the product as a red solid.

2.4. Biochemical and Biophysical Analyses. Activity Assay. The activity assay was performed following a procedure previously described in ref 19 . Chemically denatured myoglobin was prepared by adding $570 \mathrm{mg}$ of guanidine- $\mathrm{Cl}$ and $0.5 \mathrm{mg}$ of myoglobin to $1 \mathrm{~mL}$ of DPBS solution. The solution was stirred at room temperature for 30 $\mathrm{min}$ and then filtered with syringe filters of $0.45 \mu \mathrm{m}$. The activity was expressed as the percentage of the absorbance recorded for each sample referred to the native protein's value. The negative control was obtained by performing the activity assay on the solution in the absence of the protein. We prepared solutions with the expected amount of free polymer in DPBS and performed the procedure indicated above. We obtained equal values for all the polymers; therefore, we reported the value obtained for the polymer PMeEP, as representative for all PPEs. Errors were evaluated based on at least three replicas.
Proteolytic Resistance of the Conjugates. A conjugate solution containing around $0.1 \mathrm{mg} / \mathrm{mL}$ of protein inside (exact concentration measured by UV-vis spectroscopy) was prepared. The degradation was started by adding a certain amount of enzyme solution, corresponding to $2: 1 \mathrm{w} / \mathrm{w}$ of Proteinase $\mathrm{K}$. The data were recorded by a Jasco V-550 UV-vis spectrometer, acquiring a spectrum in the wavelength range $240-640 \mathrm{~nm}$ every $2 \mathrm{~min}$. The autolysis of the Proteinase K (Figure S11) was observed performing the same measurements on a solution of $300 \mu \mathrm{L}$ of Proteinase $\mathrm{K}$ and $2.7 \mathrm{~mL}$ of DPBS. The proteolytic degradation of the conjugates was compared with the one of native myoglobin, applying the same procedure on a $0.1 \mathrm{mg} / \mathrm{mL}$ solution of pure myoglobin in DPBS. The degradation of the protein over time in the absence of the proteolytic enzyme was observed performing the same measurements on a solution of myoglobin $(0.1 \mathrm{mg} / \mathrm{mL})$ in DPBS without adding the proteolytic enzyme (Figure S11).

Nano-Differential Scanning Fluorometry (Nano-DSF). Nano-DSF was performed with a Prometheus NT.48 from Nano-Temper Technologies. The instrument cell was filled with the sample solution in DPBS, with $1 \mathrm{mg} / \mathrm{mL}$ of protein inside. A thermal scan from 20 to $95{ }^{\circ} \mathrm{C}$ at $1{ }^{\circ} \mathrm{C} / \mathrm{min}$ was conducted, recording the fluorescence emission fluorescence at $350 \mathrm{~nm}$. $T_{\text {onset }}$ was evaluated as the intercept between the tangent to the derivative curve before the unfolding and the line passing by the derivative curve's first inflection point. $T_{50}$ was defined as the maximum temperature of the derivative curve's peak. Errors were evaluated based on at least three replicas.

Nano-Differential Scanning Calorimetry (Nano-DSC). Calorimetric measurements were performed with a nano-DSC III (Calorimetry Science Corporation, model CS-6300) equipped with capillary cells, at scan rate $1{ }^{\circ} \mathrm{C} / \mathrm{min}$, in the range from 25 to $90{ }^{\circ} \mathrm{C}$. The samples were tested in DPBS buffer solution at $\mathrm{pH} 7.0$ with around $1 \mathrm{mg} / \mathrm{mL}$ of protein concentration. A heating-cooling cycle was performed for all the experiments, followed by a second heating scan. The equilibration time between each ramp was set to $60 \mathrm{~s}$. All the samples were degassed and filtered before the measurements, following the standard nano-DSC procedure. ${ }^{31}$ The exact concentration of protein in solution was determined by UV-vis absorbance spectrophotometry (with a Jasco V-550 UV-vis spectrometer) by using $\varepsilon(280 \mathrm{~nm}): 1.66 \mathrm{~mL} / \mathrm{mg} \mathrm{cm},{ }^{29}$ considering that at this wavelength the polymer contribution is zero and that the protein has the same absorbance coefficient either alone or in the conjugates. The DSC blank scan was performed filling the sample and the reference cells with DPBS buffer in the same experimental conditions. Data were analyzed by using Nano-Analyze Data Analysis (version 3.11.0, T.A. Instruments) and fixed by applying fitting models with OriginPro8 SR4 (version 8, Origin Lab Corporation). More in detail, the blank measurement was subtracted from the experimental curve, and a third-grade polynomial baseline was defined. The two-state scaled model ${ }^{32}$ applied in a range of temperatures going from $55{ }^{\circ} \mathrm{C}$ to the curve maximum was used to fit the samples. The heat capacity drop $\Delta_{d} C_{p}$ was affected by a rather large error due to the lack of enough points in the denatured state of the protein, and it was therefore not taken into consideration in the present work. $T_{\text {onset }}$ and $T_{50}$ were defined as described for nano-DSF. The reversibility of the process (Rev. \%) was calculated as the ratio percentage of the peak area recorded in the first and the second heating scan. 


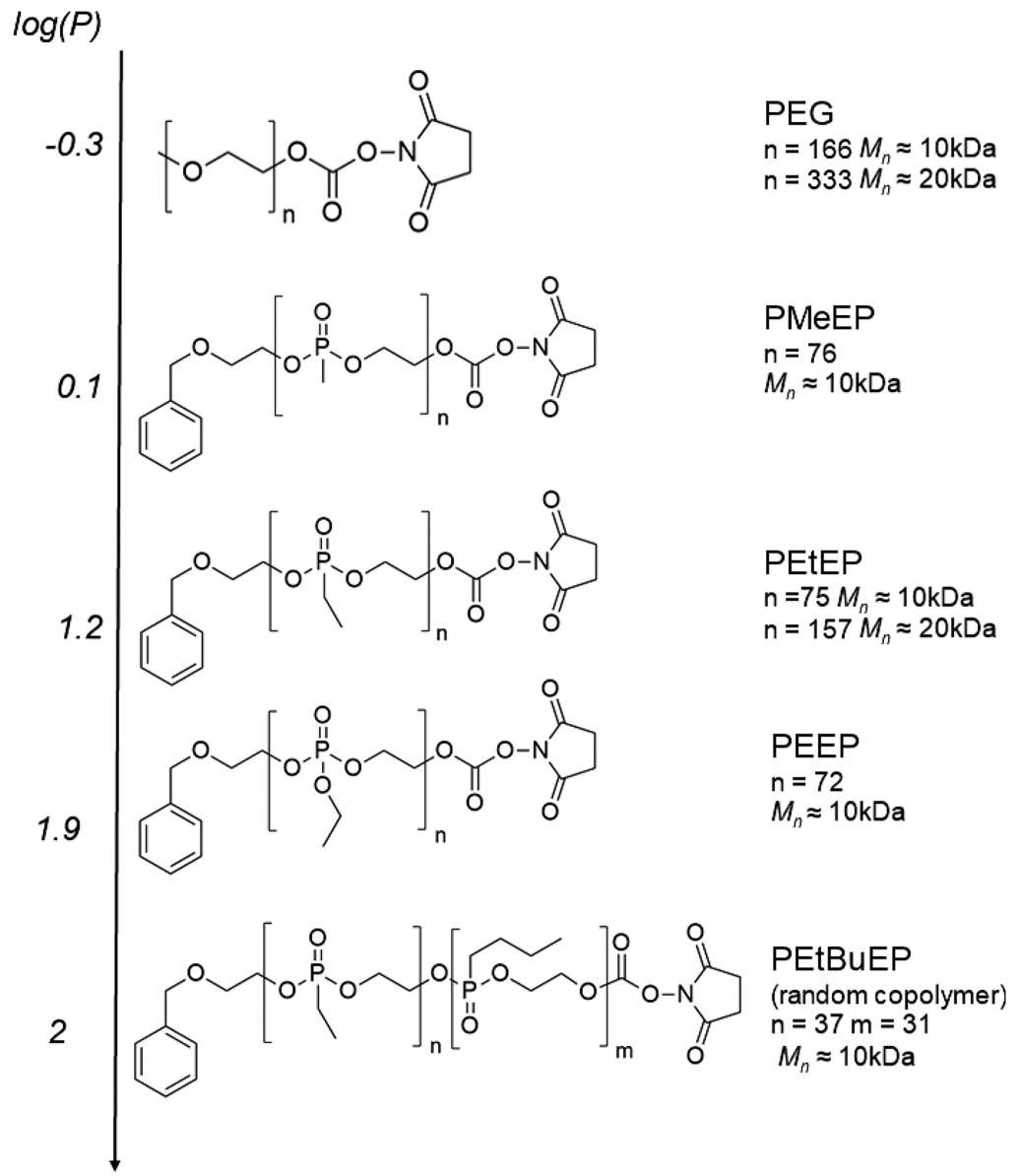

Figure 1. Set of SC-activated polymers synthesized in this work. The partition coefficient $(\log P)$ was estimated by ChemDraw 12 using a dimer of the polymer.

\section{RESULTS AND DISCUSSION}

This work is focused on the synthesis of a novel set of protein-polymer conjugates using PPEs with different molar mass and hydrophilicity. In addition, we analyzed the samples by a set of different techniques, i.e., UV-vis spectrophotometry, activity assay, nano-DSF, nano-DSC, and testing the proteolytic resistance.

3.1. Synthesis of Polymers and Conjugates. Following previously established protocols, activated PPEs were synthesized via anionic ring-opening polymerization (AROP) (Scheme 1). ${ }^{13,19,23,33-35}$ Monomers with different lateral substituent (R) were used to obtain polymers with different hydrophilicity. The activation of the $\mathrm{OH}$ end group as a succinimidyl carbonate $(-S C)$ permitted bioconjugation to myoglobin. ${ }^{6,23,30}$ The successful introduction of the SC group was detected by ${ }^{1} \mathrm{H}$ NMR or the so-called "TNBS assay". The molar mass and molar mass dispersity of polymers were verified by ${ }^{1} \mathrm{H}$ and ${ }^{31} \mathrm{P}$ NMR spectroscopy and GPC in DMF (Figures S1-S3). Commercially available poly(ethylene glycol monomethyl ether) was activated by the same procedure as outlined in the Experimental Section.

The set of activated polymers synthesized in this work is reported in Figure 1. The polymer hydrophilicity could be calculated by an experimental determination of the partition coefficient $(\log P) ;{ }^{36}$ nevertheless, these measures are often subjected to a high experimental error. ${ }^{37}$ As we intend to compare the $\log P$ values relatively between the polymers, we decided to calculate the hydrophilicity by a software tool. In addition, retention times measured by HPLC as reported previously were used to assess the polymer hydrophilicity, ${ }^{12}$ which followed the trend of the calculated $\log P$ values (see the Experimental Section).

The activated polymers were used to synthesize proteinpolymer conjugates with the model protein myoglobin of the equine skeletal muscle. The bioconjugation with the SCactivated PPEs was performed via a "grafting-to" method by the amidation of available lysine residues on the protein surface (Scheme 2). The reaction was performed for $4 \mathrm{~h}$ in aqueous borate buffer $(50 \mathrm{mM}, \mathrm{pH}=8.8)$ by using a protein/polymer ratio of 1:5. The conjugates were purified by dialysis against water $(\mathrm{MWCO}=50000 \mathrm{kDa})$ and gel permeation chromatography over Sephadex G-50.

Table 1 summarizes the features of the conjugates synthesized in this work. Samples 1-5 carry polymers with the same molar mass (ca. $10 \mathrm{kDa}$ ), sorted by the polymer hydrophilicity, going from the more hydrophilic (PEG) to the less hydrophilic copolymer PEtBuEP. Sample 4 (conjugate made by myoglobin and the polyphosphate PEEP, previously synthesized with an analogue procedure ${ }^{19}$ was included in this set to expand the polymer library. The conjugates 6 and 7 carry polymers with twice the molar mass of samples 1 and 3 and have been synthesized to evaluate polymer molar mass's influence on the protein properties.

3.2. Characterization of the Conjugates. We employed SDS-PAGE (sodium dodecyl sulfate-polyacrylamide gel 
Scheme 2. Bioconjugation Reaction of the SC-Activated Polymers and Myoglobin ${ }^{a}$<smiles>[R]OP(=O)(OCCOCc1ccccc1)OCCOC(=O)ON1C(=O)CCC1=O</smiles>

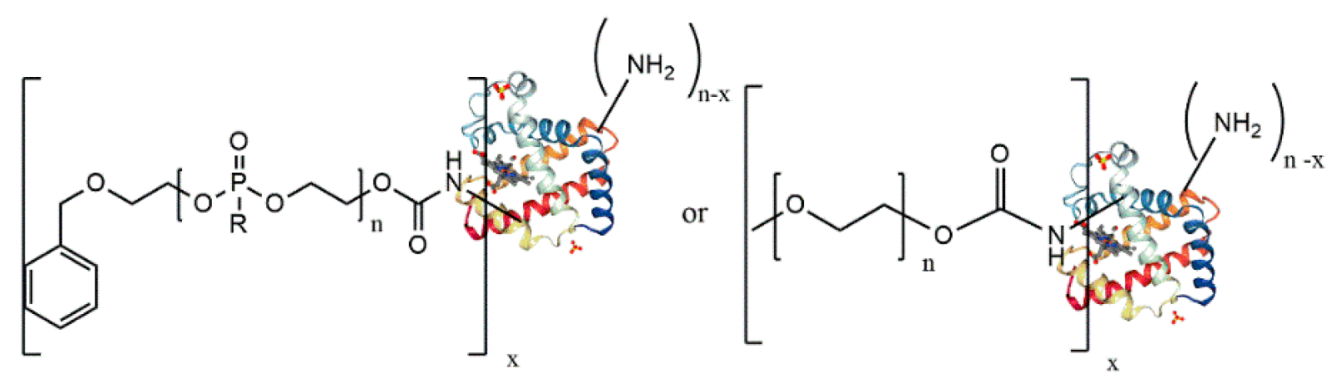

${ }^{a}$ Image of myoglobin from the RCSB PBD (rcsb.org) of PDB ID 5CN5, taken from the cited reference. ${ }^{38}$

Table 1. Characterization Data of Polymers and Conjugates Synthesized in This Work

\begin{tabular}{|c|c|c|c|c|c|c|c|c|c|c|}
\hline \multicolumn{3}{|c|}{ conjugates } & \multicolumn{8}{|c|}{ polymers } \\
\hline & \multirow[b]{2}{*}{ sample } & \multirow[b]{2}{*}{ purity $/ \%^{a}$} & \multirow[b]{2}{*}{ name } & \multirow[b]{2}{*}{$M_{\mathrm{n}}(\mathrm{NMR}) / \mathrm{kDa}^{b}$} & \multirow[b]{2}{*}{ no. of units ${ }^{b}$} & \multirow[b]{2}{*}{ yield/\% } & \multirow[b]{2}{*}{$\bigoplus^{c}$} & \multicolumn{2}{|c|}{$\%$ activation } & \multirow[b]{2}{*}{$\log P^{e}$} \\
\hline & & & & & & & & $\mathrm{TNBS}^{d}$ & $\mathrm{NMR}^{b}$ & \\
\hline 1 & My-PEG (10 kDa) & 64 & PEG & 10 & 166 & 61 & 1.1 & 73.4 & 90 & -0.3 \\
\hline 2 & My-PMeEP (10 kDa) & 98 & PMeEP & 9.6 & 76 & 99 & 1.3 & 58.3 & 100 & 0.1 \\
\hline 3 & My-PEtEP (10 kDa) & 91 & PEtEP & 10.5 & 75 & 99 & 1.2 & 57 & $>100$ & 1.2 \\
\hline 4 & My-PEEP (10 kDa) & 98 & PEEP & 11.3 & 64 & 88 & 1.1 & & $>100$ & 1.9 \\
\hline 5 & My-P(Et-Bu)EP (10 kDa) & 95 & $\mathrm{P}(\mathrm{E} t-\mathrm{Bu}) \mathrm{EP}$ & 10.4 & $37-31$ & 94 & 1.3 & & 79 & 2 \\
\hline 6 & My-PEG (20 kDa) & 60 & PEG & 20 & 333 & 86 & 1.3 & 60.2 & 98 & -0.3 \\
\hline 7 & My-PEtEP (20 kDa) & 83 & PEtEP & 21.6 & 157 & 96 & 1.1 & 57.5 & $>100$ & 1.2 \\
\hline
\end{tabular}

${ }^{a}$ Calculated by GPC in water with triple detection. The residual fraction was the unconjugated polymer that could not be removed during the Sephadex separation. ${ }^{b}$ Calculated by ${ }^{1} \mathrm{H}$ NMR. ${ }^{c}$ Molar mass dispersity, defined as $Ð=M_{\mathrm{w}} / M_{\mathrm{n}}{ }^{d}$ Calculated by the TNBS assay. RDS is below $4 \%$. Errors were evaluated on at least three replicas. ${ }^{e}$ Partition coefficient calculated by the software ChemDraw on a dimeric unit of the polymer chain.

electrophoresis), GPC in aqueous buffer with triple detection (UV-RI-MALLS), MALDI-TOF (matrix-assisted laser desorption/ionization coupled with a time-of-flight detector) spectrometry, and UV-vis absorbance measurements to characterize the conjugates.

SDS-PAGE (Figure 2) proved the successful bioconjugation reaction and the absence of unconjugated myoglobin in the samples. As typical for the grafting-to method, the PPEylated and PEGylated conjugates had a distribution of polymer chains attached. ${ }^{39}$ The molecular marker in the first lane cannot match the samples' correct molecular weight; therefore, GPC with a light scattering detector and MALDI-TOF spectrometry were used (experimental data are reported in the Supporting Information, Figures S4 and S5). The results obtained are reported in Table 2; in some samples, a residual amount of unconjugated polymer was present. Therefore, for the following analyses, the concentration was normalized to the protein amount (see purity values in Table 1).
Similar results were obtained for the molar mass and dispersity of the PPEylated conjugates by applying different techniques. MALDI-TOF revealed the distribution of the grafted polymer chains, while the values obtained from the UV-vis spectra are average values obtained considering that protein and conjugates have the same extinction coefficient at $280 \mathrm{~nm}(1.66 \mathrm{~cm} \mathrm{~mL} / \mathrm{mg})$, and the polymer extinction coefficient is zero. GPC values corroborated with the other measurements, except for samples My-PMeEP (10 kDa) and My-PEtEP $(20 \mathrm{kDa})$ that presented slightly higher values. From the data collected by these three different techniques, we assumed that the number of polymer chains attached to each protein was the average of the results obtained by the three different techniques (ca. 3 for all the samples).

3.3. Activity and Conformational Studies. The protein activity and conformation were analyzed by UV-vis spectrophotometry. The spectra of the conjugates, pure myoglobin, and myoglobin chemically denatured with 
a)

kDa

250

150

100

75

50

50
37

25

20

15

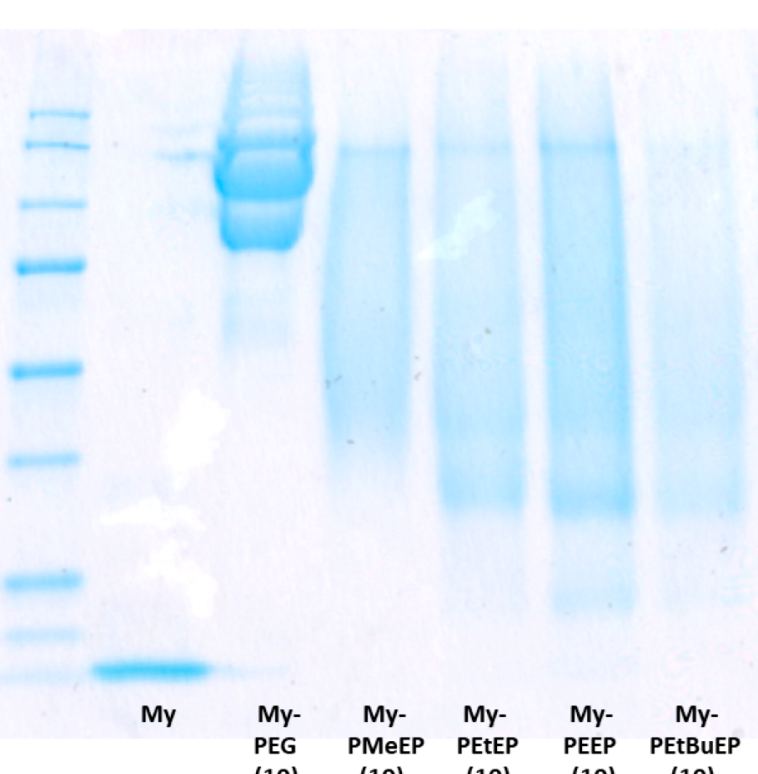

b)

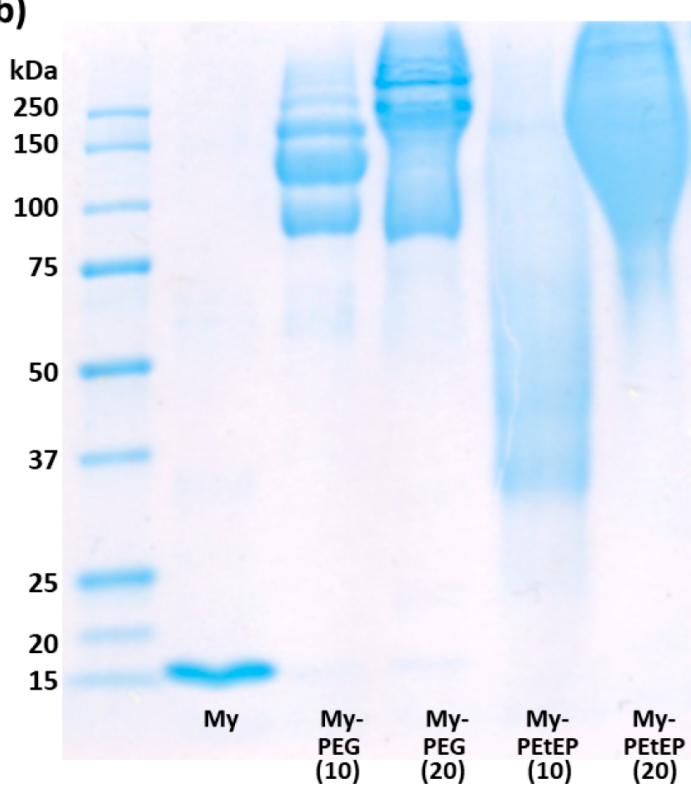

Figure 2. SDS-PAGE with Coomassie Blue staining. The samples detected are (from left to right): (a) standard, myoglobin, My-PEG (10 kDa), My-PMeEP (10 kDa), My-PEtEP (10 kDa), My-PEEP (10 kDa), My-PEtBuEP (10 kDa); (b) standard, myoglobin, My-PEG (10 kDa), My-PEG $(20 \mathrm{kDa}), \mathrm{My}-\mathrm{PEtEP}(10 \mathrm{kDa})$, My-PEtEP $(20 \mathrm{kDa})$.

Table 2. GPC, MALDI-TOF, and UV-Vis Spectrophotometry Data of the Set of Conjugates Objects of This Work

\begin{tabular}{|c|c|c|c|c|c|c|}
\hline & \multirow[b]{2}{*}{ sample } & \multicolumn{2}{|c|}{$\mathrm{GPC}^{a}$} & \multicolumn{2}{|c|}{ MALDI-TOF $^{b}$} & \multirow{2}{*}{$\begin{array}{c}\begin{array}{c}\text { abs. }(280 \\
\text { nm })^{a}\end{array} \\
\begin{array}{c}\text { no. of } \\
\text { polymers }\end{array}\end{array}$} \\
\hline & & $\begin{array}{l}M_{\mathrm{n}} / \\
\mathrm{kDa}\end{array}$ & $\begin{array}{c}\text { no. of } \\
\text { polymers }\end{array}$ & $M_{\mathrm{n}} / \mathrm{kDa}$ & $\begin{array}{c}\text { no. of } \\
\text { polymers }\end{array}$ & \\
\hline 1 & $\begin{array}{l}\text { My-PEG } \\
(10 \mathrm{kDa})\end{array}$ & 53 & 3.6 & $\begin{array}{c}47-57- \\
67\end{array}$ & $3-4-5$ & 3.6 \\
\hline 2 & $\begin{array}{c}\text { My-PMeEP } \\
(10 \mathrm{kDa})\end{array}$ & 64 & 4.7 & $40-78$ & $2-6$ & 2.9 \\
\hline 3 & $\begin{array}{l}\text { My-PEtEP } \\
(10 \mathrm{kDa})\end{array}$ & 51 & 3.4 & $37-67$ & $2-5$ & 2.6 \\
\hline 4 & $\begin{array}{l}\text { My-PEEP } \\
(10 \text { kDa })\end{array}$ & $99^{d}$ & $3.3^{d}$ & & & $2.8^{d}$ \\
\hline 5 & $\begin{array}{c}\mathrm{My}-\mathrm{P}(\mathrm{Et}- \\
\mathrm{Bu}) \mathrm{EP} \\
(10 \mathrm{kDa})\end{array}$ & 50 & 3.3 & $30-57$ & $1-4$ & 3.2 \\
\hline 6 & $\begin{array}{l}\text { My-PEG } \\
(20 \mathrm{kDa})\end{array}$ & 98 & 4 & $57-77$ & $2-3$ & 3.6 \\
\hline 7 & $\begin{array}{l}\text { My-PEtEP } \\
(20 \mathrm{kDa})\end{array}$ & 135 & 5.2 & $43-84$ & $1-3$ & 3.8 \\
\hline
\end{tabular}

${ }^{a}$ The values reported are average values, and they include all the microstructures present. ${ }^{b}$ The numbers in bold are referred to the most abundant peak. ${ }^{c}$ The number of polymer chains comes from an arithmetic calculation, and it is reported with an average value of \pm 0.5 polymer chain. ${ }^{d}$ values of GPC and Absorbance taken from the cited references. ${ }^{19,20}$

guanidinium chloride, normalized for the protein content, are reported in Figure 3.

The spectra of the native protein and conjugates exhibited an intense absorption band with a maximum at $409 \mathrm{~nm}$ (the so-called Soret band) due to the $\pi-\pi^{*}$ transition of the porphyrin ring of the heme group. ${ }^{40}$ The Soret band is an ideal tool to detect changes in the protein conformation, as it is susceptible to changes in the local environment. ${ }^{41}$ As extensively reported in the literature, upon myoglobin denaturation, a decrease in absorbance at $409 \mathrm{~nm}$ occurs because of the exposure of heme to the polar aqueous solvent. $^{42-44}$

The spectra of the PPEylated proteins showed a slight reduction of the Soret band intensity. In particular, we observed that the absorbance decreased when the hydrophobicity and the molar mass of the attached polymer increased. Further evaluations on the peroxidase-like activity of myoglobin confirmed the results (Figure 4). ${ }^{45}$

All conjugates exhibited activity values higher than $68 \%$. The enzymatic activity reduction is a common item in the bioconjugation field. The lower activity of myoglobin in the conjugates might be explained by a reduced accessibility of the active-site and/or changes in the protein tertiary structure. ${ }^{46}$ In general, high activity retention is preferred in the conjugates for their final application, but activity is only one of the aspects to be considered when evaluating a new drug. As an example, the PEGylated $\alpha$-interferon (an FDA-approved drug under the trade name Pegasys) retains only $7 \%$ of native protein activity, but it is still preferred to the unmodified drug for the significant improvements of the pharmacokinetics. ${ }^{47}$

Looking at Figure 4, we observed that the conjugate MyPMeEP exhibited the same residue activity as the PEGylated analogue. The activity value decreased when decreasing the polymer hydrophilicity (see Figure 4 and Figure S6), in analogy with UV-vis data. Besides, conjugates bearing higher molar mass polymers resulted in lower residual activity due to the active site's higher shielding.

3.4. Thermal Stability of the Conjugates. Nano-DSF and nano-DSC were employed to assess the thermal stability of the conjugates. Nano-DSF studies the protein unfolding process by monitoring the intrinsic fluorescence of the aromatic amino acids tryptophan and tyrosine. The fluorescence intensity depends on the residues' chemical surroundings; therefore, it is a valuable tool to evaluate the protein unfolding process. ${ }^{48}$ The fluorescence emission at 350 $\mathrm{nm}$ of myoglobin and the conjugates was detected during a thermal scan at a constant heating rate (Figure S7). $T_{\text {onset }}$ and 


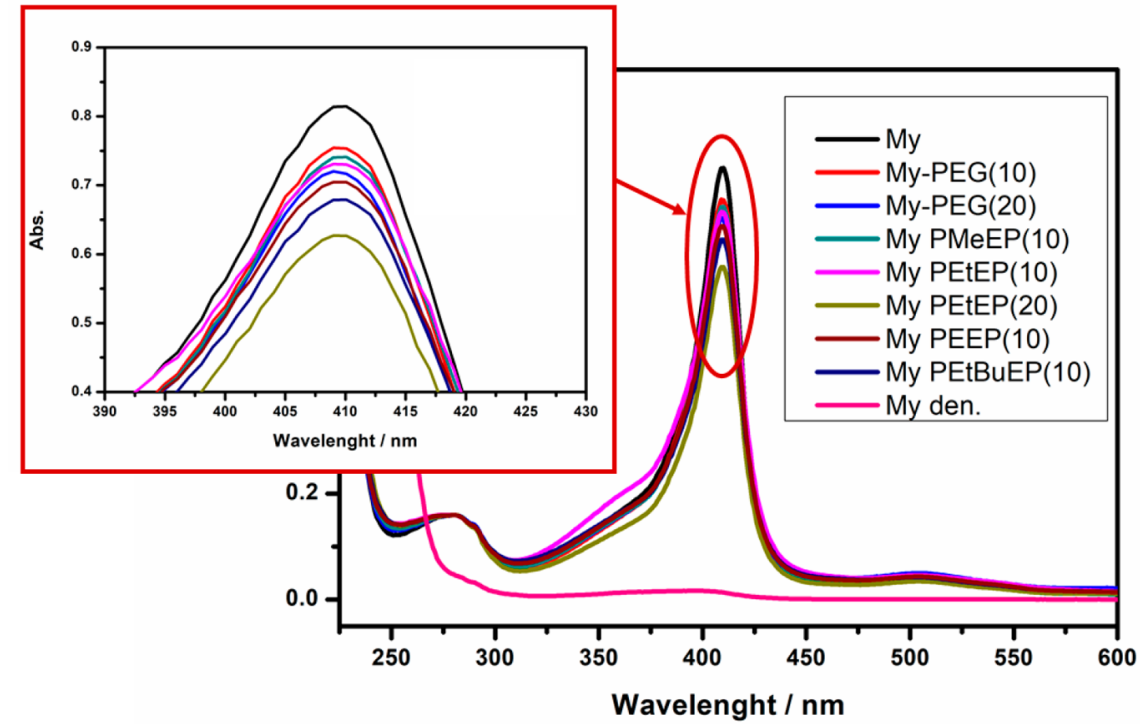

Figure 3. UV-vis absorbance spectra of myoglobin (My), denatured myoglobin (My-Den), and conjugates, normalized for the protein content, with a zoom in the region $390-430 \mathrm{~nm}$.

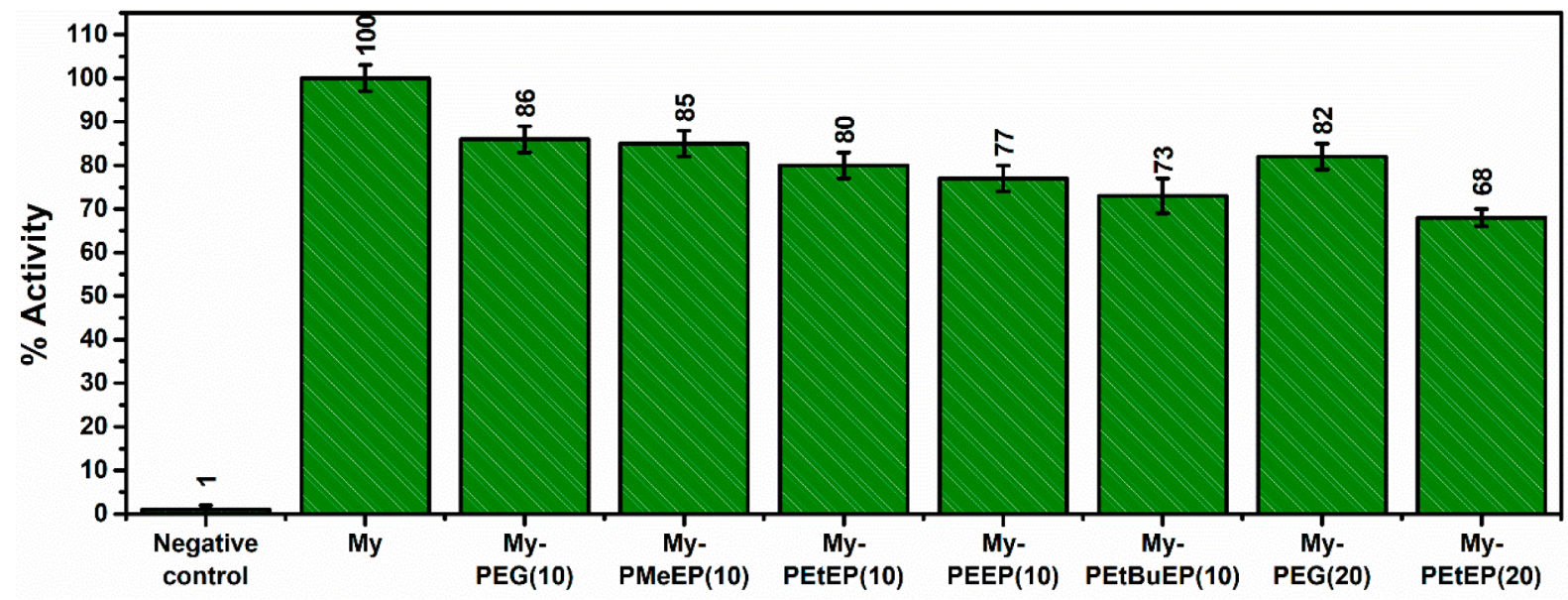

Figure 4. Activity assay performed on native myoglobin and PEGylated and PPEylated conjugates. The results are expressed as a percentage of the active protein and average of at least three independent measurements, reported in a confidence interval of 95\%. The first line (negative control) was obtained by performing the activity assay on the solution in the absence of protein, as described in the Experimental Section. Further details are reported in Table S1.

$T_{50}$ (respectively the temperature of the unfolding beginning and the middle point of the unfolding process) were calculated from the signal derivative and reported in Figure 5.

All conjugates showed a reduction of the thermal stability compared to native protein (reduction of $T_{50}$ and $T_{\text {onset }}$ ). Moreover, myoglobin's transition appeared to be narrower, suggesting the early onset of the protein fluctuations caused by the covalent attachment of the polymers. This effect had been reported previously for protein-polymer conjugates in the dry state $^{20,21}$ and proteins in hydrated powders. ${ }^{49,50}$ In analogy with previous techniques, we observed a more substantial reduction of protein stability with increasing the polymer hydrophobicity (Figure S6). The polymers' molar mass did not seem to have a remarkable effect on the PEGylated conjugates (the differences are within the experimental error). In contrast, the effect was not negligible for the polymer PEtEP, for which an increase in molar mass resulted in a significant reduction of protein stability.
The samples' thermal stability was also assessed by nanoDSC, a pivotal technique to determine the energetics of protein unfolding in solution and its thermodynamic mechanisms. ${ }^{51}$ Nano-DSC permitted the evaluation of the thermal stability by measuring the $T_{\text {onset }}$ and the $T_{50}$, in comparison with the results obtained by nano-DSF. Further evaluations permitted us to obtain information about the thermal reversibility, the mechanism, and the enthalpy of the unfolding process by performing a fitting procedure with appropriate thermodynamic models.

The samples were subjected to a heating-cooling cycle at a constant rate, followed by a second heating scan. The thermograms recorded presented an endothermic peak with a bell shape, typical for globular proteins' unfolding process. ${ }^{51}$ We calculated $T_{\text {onset }}$ and $T_{50}$ for all the samples, following the procedure reported for nano-DSF measurements. The data obtained by the two techniques (Table S1) were in accordance, except for slight differences due to instrumental features; i.e., calorimetry records all the phenomena that 


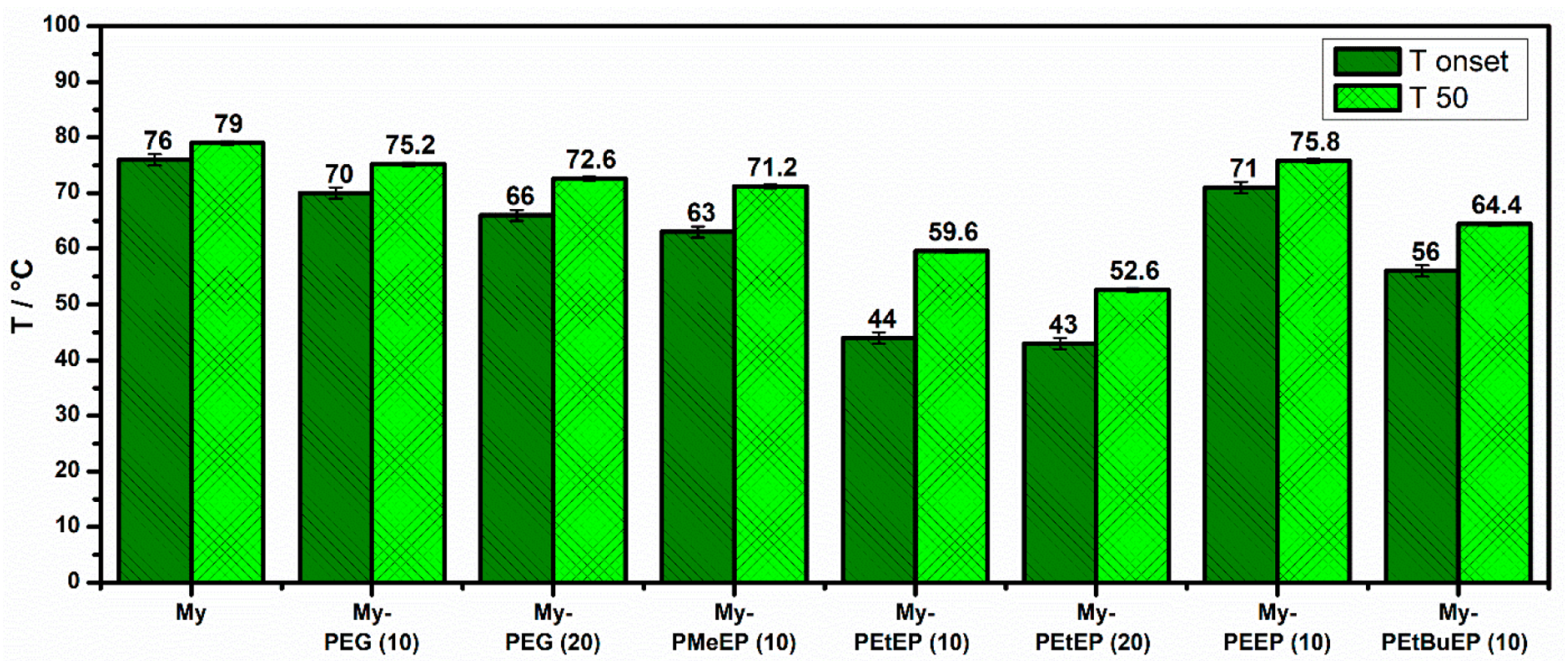

Figure 5. $T_{\text {onset }}$ and the $T_{50}$ of native myoglobin and conjugates determined by nano-DSF measurements. The results are reported with an error of $\pm 1{ }^{\circ} \mathrm{C}$ for $T_{\text {onset }}$ and $\pm 0.3{ }^{\circ} \mathrm{C}$ for $T_{50}$. Further details are reported in Table S1.

involve heat exchange with the environment, while fluorometry follows the process monitoring changes in the tryptophan surrounding.

Besides, we calculated the reversibility index (Rev. \%) of the process (Table 3 ), defined as the ratio percentage of the peak

Table 3. Experimental and Best-Fit Parameters Obtained by Analyzing Native Myoglobin and Conjugates by Nano-DSC

\begin{tabular}{|c|c|c|c|c|c|}
\hline \multirow{2}{*}{\multicolumn{2}{|c|}{ sample }} & \multicolumn{2}{|c|}{$\begin{array}{l}\text { experimental } \\
\text { curve }\end{array}$} & \multicolumn{2}{|c|}{$\begin{array}{l}\text { best fit parameters } 2 \\
\text { state model }\end{array}$} \\
\hline & & $\begin{array}{l}T_{50} / \\
{ }^{\circ} \mathrm{C}^{a}\end{array}$ & $\begin{array}{l}\text { Rev. } \\
\%^{b}\end{array}$ & $\begin{array}{c}\Delta^{\circ} \mathrm{H} / \\
\mathrm{kJ} \mathrm{mol}^{-1 c}\end{array}$ & $\begin{array}{l}T_{50} / \\
{ }^{\circ} \mathrm{C}^{a}\end{array}$ \\
\hline Мy & myoglobin & 79.9 & 26 & 552 & 80.2 \\
\hline 1 & My-PEG (10 kDa) & 75.5 & 81 & 391 & 75.8 \\
\hline 2 & My-PMeEP $(10 \mathrm{kDa})$ & 74.5 & 83 & 320 & 74.5 \\
\hline 3 & My-PEtEP (10 kDa) & 72.9 & 74 & 299 & 73.0 \\
\hline 4 & My-PEEP $(10 \mathrm{kDa})$ & 62.7 & 15 & & \\
\hline 5 & $\begin{array}{l}\text { My-P(Et-Bu)EP } \\
(10 \mathrm{kDa})\end{array}$ & 58.2 & 37 & & \\
\hline 6 & My-PEG (20 kDa) & 76.6 & 73 & 409 & 76.7 \\
\hline 7 & My-PEtEP (20 kDa) & 60.0 & 63 & & \\
\hline
\end{tabular}

${ }^{a}$ Data reported with an error bar of $\pm 0.3{ }^{\circ} \mathrm{C}$. ${ }^{b}$ Data reported with an error bar of \pm 2 percentage points. ${ }^{c}$ Data reported within an RSD of $5 \%$.

area recorded in two subsequent heating scans. ${ }^{52}$ We observed that the native protein had a low reversibility index (26\%), highlighted by visible precipitation in the solution recovered after the thermal scan. Samples My-PEEP (10 kDa) and MyPEtBuEP $(10 \mathrm{kDa})$ presented a similar behavior, while samples My-PEG (10 kDa), My-PMeEP (10 kDa), My-PEtEP (10 $\mathrm{kDa})$, and My-PEG (20 kDa) showed a remarkable increase of the Rev. \% without visible precipitation in the solution recovered after the thermal scan (Figure S8). Overall, the thermal reversibility decreased when increasing the polymer molar mass and hydrophobicity, following the systematic trend observed in the previous paragraphs. The reduction of Rev. \% could be caused by irreversible processes occurring during the unfolding process, e.g., intramolecular aggregation and protein precipitation. This is a common scenario in many globular proteins, in which the formation of aggregates permits to minimize the repulsive forces among the hydrophobic residues (exposed to the aqueous solvent during the unfolding process) and the solvent itself. ${ }^{53}$ The recorded signal is the sum of the endothermic unfolding process and the exothermic precipitation phenomena; therefore, it results in an asymmetrical bell profile.

Conscious of the incomplete process reversibility, we attempted a thermodynamic analysis of the thermograms of the native protein and the conjugates to gather more information about the unfolding mechanism. We based the analysis on the assumption (valid for similar PEGylated systems reported in the literature $)^{54}$ that the irreversible aggregation processes occurred at the end of the unfolding process; therefore, they affected only the second half of the thermogram. Following this concept, we performed a deconvolution procedure applying a two-state unfolding model on the curve's early part. Figure 6 shows the fitting performed on the native protein and the conjugates My-PEG (10 kDa), My-PMeEP (10 kDa), My-PEtEP (10 kDa), and My-PEG $(20 \mathrm{kDa})$. The fitting on samples My-PEtEP (10 $\mathrm{kDa}$ ), My-PEtBuEP (10 kDa), and My-PEtEP (20 kDa) did not provide satisfactory results with any statistical deconvolution model, standard for protein unfolding (data not reported).

The procedure was considered to be reliable as it rebuilds with low error the first part of the curve, while the experimental curve drops more rapidly in the second part of the thermogram for the presence of concomitant exothermic aggregation phenomena. The differences between the experimental and the theoretical curves are minor in the conjugates than native myoglobin because in these samples the process reversibility increases (Table 3) and the protein aggregation decreases, confirming the two-state unfolding model validity. Table 3 summarizes the best-fitting parameters. The results obtained for native myoglobin were in line with those reported in the literature. $^{27,54}$ The conjugates showed a reduction in $T_{\text {onset }}$ $T_{50}$, and enthalpy values, denoting a destabilizing effect provoked by the polymer's presence. The destabilization increased with the increase in the polymer hydrophobicity $\left(\Delta^{\circ} H_{\text {My-PEG(10) }}>\Delta^{\circ} H_{\text {My-PMeEP(10) }}>\Delta^{\circ} H_{\text {My-PEtEP(10) }}\right.$; see Figure $\mathrm{S} 6)$, in line with the other measurements reported above. Changes in the polymer molar mass (PEG of 10 or $20 \mathrm{kDa}$ ) indicated a slight increase of $T_{50}$ and $\Delta^{\circ} H$, which nevertheless were in the experimental error. 

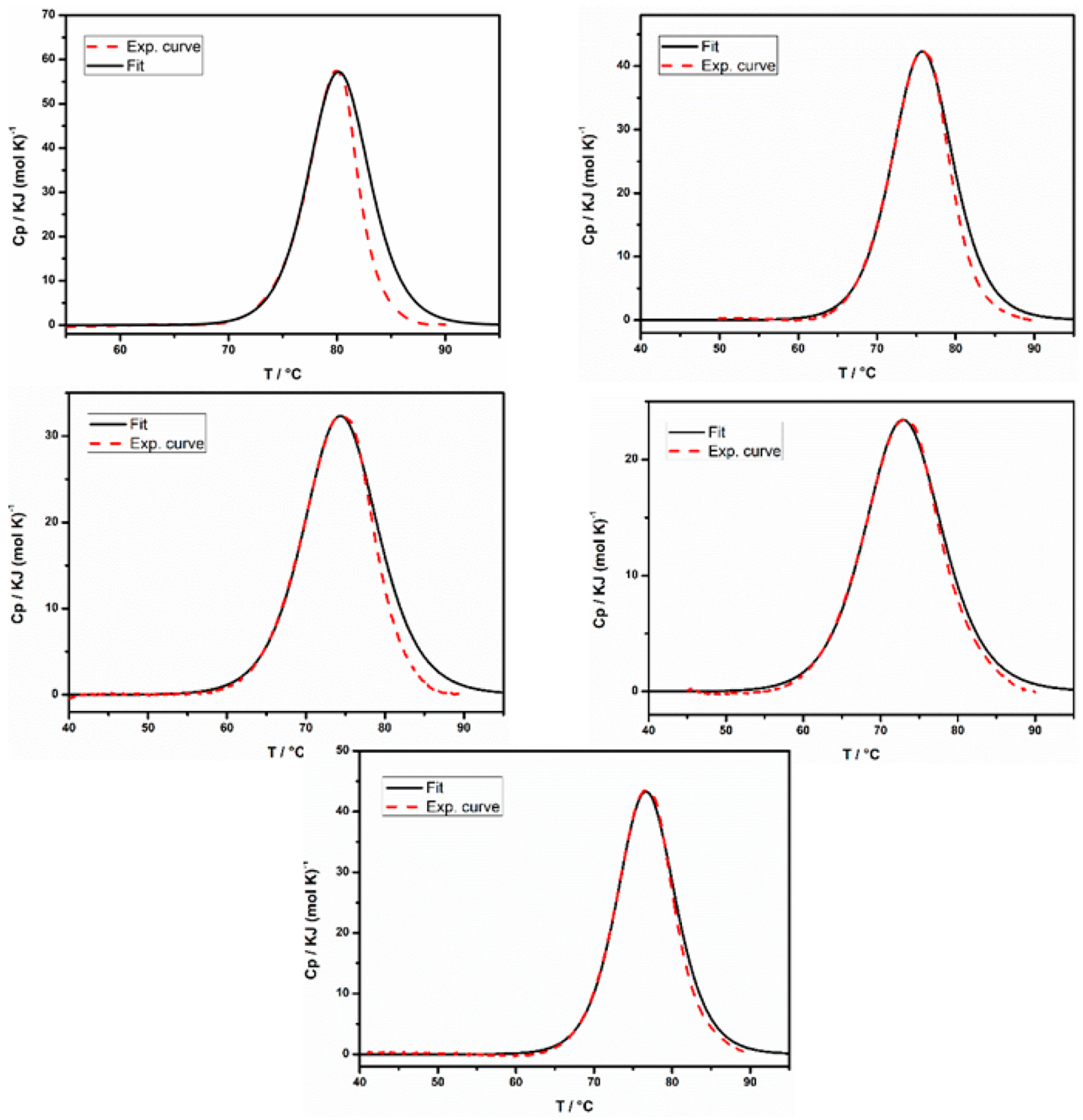

Figure 6. Deconvolution procedure with a two-state unfolding model for the samples (from top left to bottom right): myoglobin, My-PEG (10 $\mathrm{kDa})$, My-PMeEP (10 kDa), My-PEtEP (10 kDa), and My-PEG (20 kDa).

Overall, nano-DSC indicated that polymers' covalent attachment induced a slight reduction of the protein thermal stability; nevertheless, the unfolding mechanism did not change, but it remained a two-stage process. Besides, the more hydrophilic polymers (PEG of 10 and $20 \mathrm{kDa}, \mathrm{PMeEP}$ and PEtEP of $10 \mathrm{kDa}$ ) acted as a shield around the protein, protecting it from the irreversible aggregation effects induced by high temperatures. On the contrary, the conjugates made with the (co)polymers PEEP and PEtBuEP, more hydrophobic, exhibited a lower reversibility index. We assume that hydrophobic polymeric residues tend to minimize the interactions with the aqueous environment interacting with more hydrophobic amino acid residues typically hidden from the surface, with an overall weakening of the system.

3.5. Proteolytic Resistance. Finally, we evaluated the degradation rate of native myoglobin and the set of conjugates in the presence of Proteinase K (a serine protease with a broad degradation spectrum $)^{55}$ to obtain information about the polymer's protective action on the protein. SDS-PAGE confirmed protein degradation in the presence of Proteinase $\mathrm{K}$ (Figure S9). The degradation rate was monitored by recording UV-vis absorbance spectra over time (Figure S10), which exhibit a reduction in the Soret band intensity over time, related to the loss of tertiary protein conformation around the 
a)

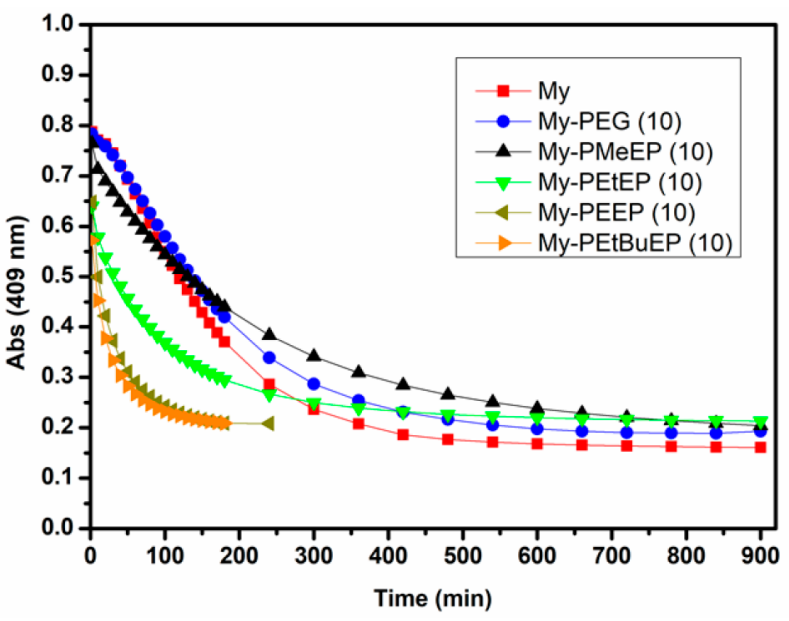

b)

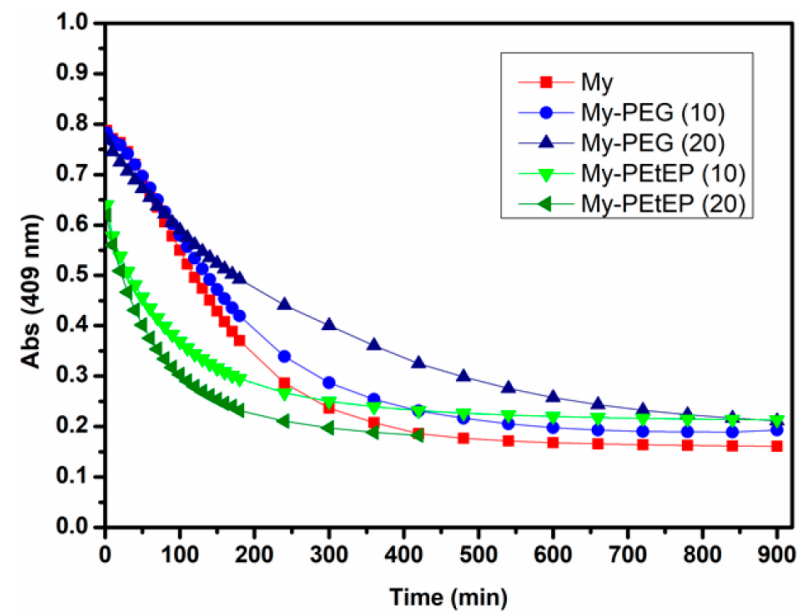

Figure 7. Degradation profiles of native myoglobin and conjugates degraded by Proteinase K, monitoring the absorbance signal's intensity at 409 $\mathrm{nm}$ over time. The signals are normalized for the protein concentration by using the absorbance signal at 280 nm. The images show the polymer hydrophilicity's influence on the conjugates' degradation rate (a) and the polymer molar mass's influence on the conjugates' degradation rate (b).

active group and the reduction of protein activity, as discussed in the previous paragraphs. We evaluated the effect of polymer hydrophilicity on the degradation process (Figure 7a) and the effect of polymer molar mass (Figure $7 \mathrm{~b}$ ).

The conjugates My-PEG (10 kDa), My-PMeEP (10 kDa), My-PEtEP (10 kDa), and My-PEG $(20 \mathrm{kDa})$ confirmed the protective action of the polymer toward the protein, recording high absorbance intensity with respect to the native protein after 180-250 min. The polymer molar mass had an opposite effect in the PEGylated and the PPEylated conjugates: in the first case, PEG of $20 \mathrm{kDa}$ slowed the degradation process; on the other hand, PEtEP of $20 \mathrm{kDa}$ induced a more pronounced degradation than PEtEP of $10 \mathrm{kDa}$. Overall, the proteolytic studies confirmed the importance of the polymer hydrophilicity on protein stability, expressed by the proteolytic protection given by the more hydrophilic polymers and the destabilization brought by the more hydrophobic polymers.

\section{CONCLUSIONS}

We prepared a systematic library of protein-polymer conjugates using PPEs and PEG of different molar mass and hydrophilicity. The conjugates were analyzed by several techniques, revealing the importance of polymer hydrophilicity on protein stability and activity. The hydrophilic PPEs exhibited similar values as the PEGylated analogues; in particular, they showed a low reduction of the residual protein activity and thermal stability, whereas they shielded the protein from the action of proteolytic enzymes and thermally induced aggregation. The thermal analyses performed by nano-DSC permitted a complete study of the unfolding mechanism, pointing out that the covalent attachment of hydrophilic polymer enhanced the process reversibility, which nevertheless remained a two-stage process. The protein conjugated with the polymer PMeEP exhibited the best results, standing out among the other PPEs as a promising biodegradable alternative to PEG. On the contrary, we observed that less hydrophilic PPEs resulted in lower residual activity and protein stability.

Overall, the importance of an accurate choice of polymer hydrophilicity directly influences the protein's properties. Such developments help to understand the structure-property relationships in protein-polymer conjugates and will help orientate the synthesis of novel candidates for efficient proteinbased drugs.

\section{ASSOCIATED CONTENT}

\section{Supporting Information}

The Supporting Information is available free of charge at https://pubs.acs.org/doi/10.1021/acs.biomac.1c00058.

Synthetic procedures and characterization data $\left({ }^{1} \mathrm{H},{ }^{31} \mathrm{P}\right.$ NMR spectra, and GPC elugrams) for PPEs and PEG; synthetic procedures and characterization data (aqueous GPC, MALDI-TOF spectra, nano-DSF thermograms, data of activity and thermal stability obtained by nanoDSF, nano-DSC, activity assay, degradation profiles induced by Proteinase K) of native protein and conjugates; dependence of protein properties from polymer hydrophilicity; pictures of conjugates solution before and after the thermal scan performed by nanoDSC (PDF)

\section{AUTHOR INFORMATION}

\section{Corresponding Author}

Frederik R. Wurm - Sustainable Polymer Chemistry, Department of Molecules and Materials, MESA+ Institute for Nanotechnology, Faculty of Science and Technology, Universiteit Twente, 7500 AE Enschede, The Netherlands; (1) orcid.org/0000-0002-6955-8489;

Email: frederik.wurm@utwente.nl

\section{Authors}

Chiara Pelosi - Dipartimento di Chimica e Chimica Industriale, Università di Pisa, Pisa 56124, Italy; (1) orcid.org/0000-0001-5824-4372

Celia Duce - Dipartimento di Chimica e Chimica Industriale, Università di Pisa, Pisa 56124, Italy; 이이.org/00000001-9354-7993

Maria R. Tinè - Dipartimento di Chimica e Chimica Industriale, Università di Pisa, Pisa 56124, Italy

Complete contact information is available at: https://pubs.acs.org/10.1021/acs.biomac.1c00058 


\section{Notes}

The authors declare no competing financial interest.

\section{ACKNOWLEDGMENTS}

C.P. thanks the University of Pisa and the Doctoral School in Chemical Science (DSCM) for the funding given to support the period abroad at the Max-Planck-Institut für Polymerforschung (MPIP, Mainz, Germany), where parts of this work were performed. Moreover, we thank Petra Räder (MPIP) for her assistance in nano-DSF measurements and Dr. Luca Bernazzani for his assistance regarding the nano-DSC. This work was supported by the University of Pisa (project PRA_2020_17).

\section{REFERENCES}

(1) Turecek, P. L.; Bossard, M. J.; Schoetens, F.; Ivens, I. A. PEGylation of Biopharmaceuticals: A Review of Chemistry and Nonclinical Safety Information of Approved Drugs. J. Pharm. Sci. 2016, 105 (2), 460-475.

(2) Hong, L.; Wang, Z.; Wei, X.; Shi, J.; Li, C. Antibodies against Polyethylene Glycol in Human Blood: A Literature Review. J. Pharmacol. Toxicol. Methods 2020, 102, 106678.

(3) Qi, Y.; Chilkoti, A. Protein-Polymer Conjugation-Moving beyond PEGylation. Curr. Opin. Chem. Biol. 2015, 28, 181-193.

(4) Garvey, L. H.; Nasser, S. Anaphylaxis to the First COVID-19 Vaccine: Is Polyethylene Glycol (PEG) the Culprit ? Br. J. Anaesth. 2021, 126 (3), e106-e108.

(5) Knop, K.; Hoogenboom, R; Fischer, D.; Schubert, U. S. Poly(Ethylene Glycol) in Drug Delivery: Pros and Cons as Well as Potential Alternatives. Angew. Chem., Int. Ed. 2010, 49 (36), 62886308.

(6) Viegas, T. X.; Bentley, M. D.; Harris, J. M.; Fang, Z.; Yoon, K.; Dizman, B.; Weimer, R.; Mero, A.; Pasut, G.; Veronese, F. M. Polyoxazoline: Chemistry, Properties, and Applications in Drug Delivery. Bioconjugate Chem. 2011, 22 (5), 976-986.

(7) Richard, A.; Margaritis, A. Poly(Glutamic Acid) for Biomedical Applications. Crit. Rev. Biotechnol. 2001, 21 (4), 219-232.

(8) Duncan, R.; Vicent, M. J. Do HPMA Copolymer Conjugates Have a Future as Clinically Useful Nanomedicines? A Critical Overview of Current Status and Future Opportunities. Adv. Drug Delivery Rev. 2010, 62 (2), 272-282.

(9) Pelosi, C.; Tinè, M. R.; Wurm, F. R. Main-Chain Water-Soluble Polyphosphoesters: Multi-Functional Polymers as Degradable PEGAlternatives for Biomedical Applications. Eur. Polym. J. 2020, 141, 110079.

(10) Bauer, K. N.; Tee, H. T.; Velencoso, M. M.; Wurm, F. R. MainChain Poly(Phosphoester)s: History, Syntheses, Degradation, Bioand Flame-Retardant Applications. Prog. Polym. Sci. 2017, 73, 61122.

(11) Schöttler, S.; Becker, G.; Winzen, S.; Steinbach, T.; Mohr, K.; Landfester, K.; Mailänder, V.; Wurm, F. R. Protein Adsorption Is Required for Stealth Effect of Poly(Ethylene Glycol)- and Poly(Phosphoester)-Coated Nanocarriers. Nat. Nanotechnol. 2016, 11 (4), 372-377.

(12) Simon, J.; Wolf, T.; Klein, K.; Landfester, K.; Wurm, F. R.; Mailänder, V. Hydrophilicity Regulates the Stealth Properties of Polyphosphoester-Coated Nanocarriers. Angew. Chem., Int. Ed. 2018, 57 (19), 5548-5553.

(13) Wolf, T.; Steinbach, T.; Wurm, F. R. A Library of Well-Defined and Water-Soluble Poly(Alkyl Phosphonate)s with Adjustable Hydrolysis. Macromolecules 2015, 48 (12), 3853-3863.

(14) Yao, M.; Ma, Y.; Liu, H.; Khan, M. I.; Shen, S.; Li, S.; Zhao, Y.; Liu, Y.; Zhang, G.; Li, X.; Zhong, F.; Jiang, W.; Wang, Y. Enzyme Degradable Hyperbranched Polyphosphoester Micellar Nanomedicines for NIR Imaging-Guided Chemo-Photothermal Therapy of Drug-Resistant Cancers. Biomacromolecules 2018, 19 (4), 1130-1141.
(15) Bauer, K. N.; Liu, L.; Wagner, M.; Andrienko, D.; Wurm, F. R. Mechanistic Study on the Hydrolytic Degradation of Polyphosphates. Eur. Polym. J. 2018, 108, 286-294.

(16) Liu, Z.; Wu, M.; Xue, Y.; Chen, C.; Wurm, F. R.; Lan, M.; Zhang, W. Hydrophilic Polyphosphoester-Conjugated Fluorinated Chlorin as an Entirely Biodegradable Nano-Photosensitizer for Reliable and Efficient Photodynamic Therapy. Chem. Commun. 2020, 56 (16), 2415-2418.

(17) Borguet, Y. P.; Khan, S.; Noel, A.; Gunsten, S. P.; Brody, S. L.; Elsabahy, M.; Wooley, K. L. Development of Fully Degradable Phosphonium-Functionalized Amphiphilic Diblock Copolymers for Nucleic Acids Delivery. Biomacromolecules 2018, 19 (4), 1212-1222.

(18) Riva, R.; Shah, U.; Thomassin, J. M.; Yilmaz, Z.; Lecat, A.; Colige, A.; Jérôme, C. Design of Degradable Polyphosphoester Networks with Tailor-Made Stiffness and Hydrophilicity as Scaffolds for Tissue Engineering. Biomacromolecules 2020, 21 (2), 349-355.

(19) Pelosi, C.; Duce, C.; Russo, D.; Tiné, M. R. R.; Wurm, F. R. R. PPEylation of Proteins: Synthesis, Activity, and Stability of Myoglobin-Polyphosphoester Conjugates. Eur. Polym. J. 2018, 108, 357-363.

(20) Russo, D.; Pelosi, C.; Wurm, F. R.; Frick, B.; Ollivier, J.; Teixeira, J. Insight into Protein-Polymer Conjugate Relaxation Dynamics: The Importance of Polymer Grafting. Macromol. Biosci. 2020, 20 (6), 1900410.

(21) Russo, D.; Plazanet, M.; Teixeira, J.; Moulin, M.; Härtlein, M.; Wurm, F. R.; Steinbach, T. Investigation into the Relaxation Dynamics of Polymer-Protein Conjugates Reveals Surprising Role of Polymer Solvation on Inherent Protein Flexibility. Biomacromolecules 2016, 17 (1), 141-147.

(22) Steinbach, T.; Wurm, F. R. Degradable PolyphosphoesterProtein Conjugates: "PPEylation" of Proteins. Biomacromolecules 2016, 17 (10), 3338-3346.

(23) Steinbach, T.; Becker, G.; Spiegel, A.; Figueiredo, T.; Russo, D.; Wurm, F. R. Reversible Bioconjugation: Biodegradable Poly(Phosphate)-Protein Conjugates. Macromol. Biosci. 2017, 17, 1600377.

(24) Sedlacek, O.; de la Rosa, V. R.; Hoogenboom, R. Poly(2Oxazoline)-Protein Conjugates. Eur. Polym. J. 2019, 120 (July), 109246.

(25) Konieczny, S.; Krumm, C.; Doert, D.; Neufeld, K.; Tiller, J. C. Investigations on the Activity of Poly(2-Oxazoline) Enzyme Conjugates Dissolved in Organic Solvents. J. Biotechnol. 2014, 181, $55-63$.

(26) Privalov, P. L.; Khechinashvili, N. N. A Thermodynamic Approach to the Problem of Stabilization of Globular Protein Structure: A Calorimetric Study. J. Mol. Biol. 1974, 86 (3), 665-684.

(27) Mehl, A. F.; Crawford, M. A.; Zhang, L. Determination of Myoglobin Stability by Circular Dichroism Spectroscopy: Classic and Modern Data Analysis. J. Chem. Educ. 2009, 86 (5), 600-602.

(28) Mozzarelli, A.; Ronda, L.; Faggiano, S.; Bettati, S.; Bruno, S. Haemoglobin-Based Oxygen Carriers: Research and Reality towards an Alternative to Blood Transfusions. Blood Transfus. 2010, 8 (SUPPL. 3), 59-68.

(29) Tanner, J. W.; Liebman, P. A.; Eckenhoff, R. G. Volatile Anesthetics Alter Protein Stability. Toxicol. Lett. 1998, 100-101, 387-391.

(30) Miron, T.; Wilchek, M. A Simplified Method for the Preparation of Succinimidyl Carbonate Polyethylene Glycol for Coupling to Proteins. Bioconjugate Chem. 1993, 4 (6), 568-569.

(31) Cooper, A.; Nutley, M. A.; Wadood, A. Differential Scanning Microcalorimetry. In Protein-Ligand Interactions: Hydrodynamics and Calorimetry; Harding, S. E., Chowdhry, B. Z., Eds.; Oxford University Press: New York, 2000; pp 287-318.

(32) Fessas, D.; Iametti, S.; Schiraldi, A.; Bonomi, F. Thermal Unfolding of Monomeric and Dimeric Beta-Lactoglobulins. Eur. J. Biochem. 2001, 268, 5439-5448.

(33) Steinbach, T.; Ritz, S.; Wurm, F. R. Water-Soluble Poly(Phosphonate)s via Living Ring-Opening Polymerization. ACS Macro Lett. 2014, 3 (3), 244-248. 
(34) Wolf, T.; Hunold, J.; Simon, J.; Rosenauer, C.; Hinderberger, D.; Wurm, F. R. Temperature Responsive Poly(Phosphonate) Copolymers: From Single Chains to Macroscopic Coacervates. Polym. Chem. 2018, 9 (4), 490-498.

(35) Bauer, K. N.; Liu, L.; Andrienko, D.; Wagner, M.; K. Macdonald, E.; P. Shaver, M.; R. Wurm, F. Polymerizing Phostones: A Fast Way to In-Chain Poly(Phosphonate)s with Adjustable Hydrophilicity. Macromolecules 2018, 51 (4), 1272-1279.

(36) Sedlacek, O.; Janouskova, O.; Verbraeken, B.; Hoogenboom, R. Straightforward Route to Superhydrophilic Poly(2-Oxazoline)s via Acylation of Well-Defined Polyethylenimine. Biomacromolecules 2019, 20 (1), 222-230.

(37) Schönsee, C. D.; Bucheli, T. D. Experimental Determination of Octanol-Water Partition Coefficients of Selected Natural Toxins. J. Chem. Eng. Data 2020, 65 (4), 1946-1953.

(38) Barends, T. R. M.; Foucar, L.; Ardevol, A.; Nass, K.; Aquila, A.; Botha, S.; Doak, R. B.; Falahati, K.; Hartmann, E.; Hilpert, M.; Heinz, M.; Hoffmann, M. C.; Kofinger, J.; Koglin, J. E.; Kovacsova, G.; Liang, M.; Milathianaki, D.; Lemke, H. T.; Reinstein, J.; Roome, C. M.; Shoeman, R. L.; Williams, G. J.; Burghardt, I.; Hummer, G.; Boutiet, S.; Schlichting, I. Direct Observation of Ultrafast Collective Motions in CO Myoglobin upon Ligand Dissociation. Science (80-.). 2015, 350 (6259), 445-450.

(39) Macchione, M. A.; Biglione, C.; Strumia, M. Design, Synthesis and Architectures of Hybrid Nanomaterials for Therapy and Diagnosis Applications. Polymers (Basel). 2018, 10 (5), 1-34.

(40) Sykes, P. A.; Shiue, H. C.; Walker, J. R.; Bateman, R. C. Determination of Myoglobin Stability by Visible Spectroscopy. J. Chem. Educ. 1999, 76 (9), 1283-1284.

(41) Gao, W.; Liu, W.; Mackay, J. A.; Zalutsky, M. R.; Toone, E. J.; Chilkoti, A. In Situ Growth of a Stoichiometric PEG-like Conjugate at a Protein's N-Terminus with Significantly Improved Pharmacokinetics. Proc. Natl. Acad. Sci. U. S. A. 2009, 106, 15231-15236.

(42) Culbertson, D. S.; Olson, J. S. The Role of Heme in the Unfolding and Assembly of Myoglobin. Biochemistry 2010, 49 (29), 6052-6063.

(43) Anderson, A. B.; Robertson, C. R. Absorption Spectra Indicate Conformational Alteration of Myoglobin Adsorbed on Polydimethylsiloxane. Biophys. J. 1995, 68 (5), 2091-2097.

(44) Ahmad, F. Complexities in the Denaturation of Horse Metmyoglobin by Guanidine Hydrochloride. J. Biol. Chem. 1985, 260 (19), 10458-10460.

(45) Carlsen, C. U.; Skovgaard, I. M.; Skibsted, L. H. Pseudoperoxidase Activity of Myoglobin: Kinetics and Mechanism of the Peroxidase Cycle of Myoglobin with $\mathrm{H}_{2} \mathrm{O} 2$ and 2,2-AzinoBis(3-Ethylbenzthiazoline-6-Sulfonate) as Substrates. J. Agric. Food Chem. 2003, 51 (19), 5815-5823.

(46) Wright, T. A.; Page, R. C.; Konkolewicz, D. Polymer Conjugation of Proteins as a Synthetic Post-Translational Modification to Impact Their Stability and Activity. Polym. Chem. 2019, 10 (4), 434-454.

(47) Bell, S. J.; Fam, C. M.; Chlipala, E. A.; Carlson, S. J.; Lee, J. I.; Rosendahl, M. S.; Doherty, D. H.; Cox, G. N. Enhanced Circulating Half-Life and Antitumor Activity of a Site-Specific Pegylated Interferon- $\alpha$ Protein Therapeutic. Bioconjugate Chem. 2008, 19 (1), 299-305.

(48) Williams, C.; Dougherty, M. L.; Makaroff, K.; Stapleton, J.; Konkolewicz, D.; Berberich, J. A.; Page, R. C. Strategies for Biophysical Characterization of Protein-Polymer Conjugates, 1st ed.; Elsevier Inc.: 2017; Vol. 590.

(49) Saitta, F.; Signorelli, M.; Bramanti, E.; Pizzimenti, S.; Pelosi, C.; Duce, C.; Fessas, D.; Bonaduce, I.; Tinè, M. R. DSC on OvalbuminHematite "Tempera" Paints: The Role of Water and Pigment on Protein Stability. Thermochim. Acta 2020, 694, 178780.

(50) Fomina, M.; Schirò, G.; Cupane, A.; Paciaroni, A.; Cinelli, S.; Cornicchi, E.; De Francesco, A.; Onori, G. Hydration Dependence of Myoglobin Dynamics Studied with Elastic Neutron Scattering, Differential Scanning Calorimetry and Broadband Dielectric Spectroscopy. Chem. Phys. Lett. 2005, 185 (4-6), 25-31.
(51) Privalov, P. L.; Dragan, A. I. Microcalorimetry of Biological Macromolecules. Biophys. Chem. 2007, 126, 16-24.

(52) Barone, G.; Del Vecchio, P.; Fessas, D.; Giancola, C.; Graziano, G. Theseus: A New Software Package for the Handling and Analysis of Thermal Denaturation Data of Biological Macromolecules. J. Therm. Anal. 1992, 38 (12), 2779-2790.

(53) Sanchez-Ruiz, J. M. Theoretical Analysis of Lumry-Eyring Models in Differential Scanning Calorimetry. Biophys. J. 1992, 61 (4), 921-935.

(54) Pelosi, C.; Saitta, F.; Wurm, F. R.; Fessas, D.; Tinè, M. R.; Duce, C. Thermodynamic Stability of Myoglobin-Poly(Ethylene Glycol) Bioconjugates: A Calorimetric Study. Thermochim. Acta 2019, 671, 26-31.

(55) Jo, S. M.; Wurm, F. R.; Landfester, K. Oncolytic Nanoreactors Producing Hydrogen Peroxide for Oxidative Cancer Therapy. Nano Lett. 2020, 20 (1), 526-533. 